\title{
Molecular analysis of the effects of steroid hormones on mouse meiotic prophase I progression
}

\author{
Deion M. Burks' ${ }^{1}$, Margaret R. McCoy ${ }^{1}$, Sudipta Dutta ${ }^{1,2}$, Connie J. Mark-Kappeler ${ }^{3,4}$, Patricia B. Hoyer ${ }^{3}$ and
} Melissa E. Pepling ${ }^{1 *}$ (1)

\begin{abstract}
Background: Infertility is linked to depletion of the primordial follicle pool consisting of individual oocytes arrested at the diplotene stage of meiotic prophase I surrounded by granulosa cells. Primordial germ cells, the oocyte precursors, begin to differentiate during embryonic development. These cells migrate to the genital ridge and begin mitotic divisions, remaining connected, through incomplete cytokinesis, in clusters of synchronously dividing oogonia known as germ cell cysts. Subsequently, they enter meiosis, become oocytes and progress through prophase I to the diplotene stage. The cysts break apart, allowing individual oocytes to be surrounded by a layer of granulosa cells, forming primordial follicles each containing a diplotene arrested oocyte. A large number of oocytes are lost coincident with cyst breakdown, and may be important for quality control of primordial follicle formation. Exposure of developing ovaries to exogenous hormones can disrupt cyst breakdown and follicle formation, but it is unclear if hormones affect progression of oocytes through prophase I of meiosis.
\end{abstract}

Methods: Fetal ovaries were treated in organ culture with estradiol, progesterone, or both hormones, labeled for MSY2 or Synaptonemal complex protein 3 (SYCP3) using whole mount immunocytochemistry and examined by confocal microscopy. Meiotic prophase I progression was also followed using the meiotic surface spread technique.

Results: MSY2 expression in oocytes was reduced by progesterone but not estradiol or the hormone combination. However, while MSY2 expression was upregulated during development it was not a precise marker for the diplotene stage. We also followed meiotic prophase I progression using antibodies against SYCP3 using two different methods, and found that the percent of oocytes at the pachytene stage peaked at postnatal day 1. Finally, estradiol and progesterone treatment together but not either alone in organ culture increased the percent of oocytes at the pachytene stage.

Conclusions: We set out to examine the effects of hormones on prophase I progression and found that while MSY2 expression was reduced by progesterone, MSY2 was not a precise diplotene stage marker. Using antibodies against SYCP3 to identify pachytene stage oocytes we found that progesterone and estradiol together delayed progression of oocytes through prophase I.

Keywords: Fetal oocyte development, Steroid hormones, Meiotic prophase, Diplotene arrest, Primordial follicle formation

\footnotetext{
* Correspondence: mepeplin@syr.edu

1 Department of Biology, Syracuse University, 107 College Place, Syracuse, NY

13244, USA

Full list of author information is available at the end of the article
}

(c) The Author(s). 2019 Open Access This article is distributed under the terms of the Creative Commons Attribution 4.0 International License (http://creativecommons.org/licenses/by/4.0/), which permits unrestricted use, distribution, and reproduction in any medium, provided you give appropriate credit to the original author(s) and the source, provide a link to the Creative Commons license, and indicate if changes were made. The Creative Commons Public Domain Dedication waiver (http://creativecommons.org/publicdomain/zero/1.0/) applies to the data made available in this article, unless otherwise stated. 


\section{Background}

In mammals, the primordial follicle pool present at birth represents the total germ cell population available to a female during her entire reproductive life. The differentiation of primordial germ cells into functional oocytes contained in primordial follicles is poorly understood. In the mouse embryo, primordial germ cells migrate to the female genital ridge and are then referred to oogonia once they colonize the ovary [18]. Oogonia develop in connected clusters known as cysts until 13.5 days post coitum ( $\mathrm{dpc}$ ) in the mouse and then become oocytes as they begin to enter meiosis [19]. Meiotic entry occurs in a wave from the anterior to the posterior side of the ovary $[2,15]$. The oocytes proceed through prophase I of meiosis progressing through a series of sub-phases starting with pre-meiotic interphase and then moving through leptotene, zygotene, pachytene, and eventually arresting at the diplotene stage [1]. The extended diplotene arrest often lasting years (until ovulation) is sometimes referred to as dictyate [5]. The germ cells enter diplotene arrest beginning at $17.5 \mathrm{dpc}$, which corresponds with the start of cyst breakdown $[1,8,21]$. As more germ cells arrive at diplotene and cysts begin to break down to form primordial follicles, some oocytes experience programmed cell death [20]. In late fetal and early neonatal development, cysts break apart into individual oocytes and are surrounded by somatic pregranulosa cells $[13,20]$. This results in primordial follicles each consisting of a diplotene arrested oocyte enclosed by several granulosa cells.

Mutations that disrupt meiotic prophase I progression in females affect fertility. For example, in females mutant for genes involved in recombination and repair, the germ cells do not progress beyond the pachytene stage of prophase I and eventually die resulting in infertility [18]. Also, inhibition of Synaptonemal Complex Protein 1 mRNA (Sycp1), found in synaptonemal complexes which are protein structures that hold the homologous chromosome pairs together at the pachytene stage, caused premature arrival at the diplotene stage and premature primordial follicle formation suggesting a link between cell cycle stage and primordial follicle formation [17]. However, in Stra 8 mutants meiotic entry is blocked but primordial follicles still form implying that meiosis and follicle formation are independent [7]. We found a small subset of primordial follicles with oocytes at prediplotene stages supporting the idea that oocytes do not have to reach the diplotene stage before follicles form [8].

Previous work from our lab demonstrated that estrogen or progesterone can reduce cyst breakdown and primordial follicle formation and together have an additive effect [3]. There is also some evidence that steroid hormones can affect progression through meiotic prophase I. For example, in cows, high levels of estradiol
$\left(\mathrm{E}_{2}\right)$ and progesterone $\left(\mathrm{P}_{4}\right)$ were associated with a delay in reaching the diplotene stage [26]. Supporting this, treatment of mouse embryos with the estrogenic compound, bisphenol A (BPA) caused defects in meiosis suggesting that $E_{2}$ signaling could be involved in regulating meiotic progression [23]. Estrogen receptor 2 (Esr2) mutants had meiotic defects similar to BPA treated animals suggesting that BPA acts as an ESR2 antagonist. Work from our lab found that in fetal organ culture progesterone but not estradiol delayed transit though meiotic prophase I [8].

One of the most common techniques used for meiotic staging is the histological method of hematoxylin and eosin (H\&E) staining that requires embedding in paraffin, sectioning, staining and then analysis of ovary sections for meiotic stage. This method is tedious, time consuming and results in a loss of three dimensional structural information. A more recently used molecular technique is the surface spread assay involving lysis of the ovary to open the cells allowing labeling of chromosomes with a fluorescent marker. While this method greatly improves the ability to identify oocytes in stages of meiotic prophase I, the ovary is completely disaggregated resulting in the loss of any structural information. One reported molecular diplotene arrest marker is MSY2, an RNA binding protein expressed in germ cells [9]. MSY2 is believed to be involved in regulating mRNA stability in growing oocytes and when the gene is deleted, females become sterile [24]. Several groups have used MSY2 protein expression as an indicator that an oocyte has reached the diplotene stage of meiotic prophase I [17, 22]. Another protein used as a marker for meiotic prophase I staging is SYCP3. As the oocytes reach pachytene, the synaptonemal complex forms holding homologous chromosomes together and SYCP3 localizes in between the chromosomes. At diplotene, homologous chromosomes begin to separate remaining attached only at points of crossing over and SYCP3 becomes diffuse except for a few sites of strong staining $[4,6]$.

The objective of the work presented here was to test effects of steroid hormones, estrogen and progesterone on meiotic prophase I progression using available molecular tools.

\section{Materials and methods \\ Animals}

CD-1 mice used for RNA studies were obtained from Charles River Laboratories and C57BL/6 mice used for all other studies were obtained from Jackson Laboratories. Mice were housed and bred at a controlled photoperiod (14 h light, $10 \mathrm{~h}$ dark), temperature $\left(21-22^{\circ} \mathrm{C}\right)$, and humidity with food and water available ad libitum. Females were mated with males of the same strain and checked daily for vaginal plugs. Noon on the day of 
vaginal plug detection was designated as $0.5 \mathrm{dpc}$. Birth usually occurred at $19.5 \mathrm{dpc}$ and was designated as postnatal day (PND) 1. Pregnant mice were euthanized by $\mathrm{CO}_{2}$ asphyxiation for fetal ovary collection. For neonatal ovary collection, pups were euthanized by decapitation on the appropriate day. All animal protocols were approved by the Syracuse University Institutional Animal Care and Use Committee.

\section{Study design}

Mouse ovary organ culture was used to investigate the effects of hormones on oocyte meiotic prophase I progression. Ovaries were harvested at $17.5 \mathrm{dpc}$ and cultured for 5 days in DMSO, $\mathrm{E}_{2}, \mathrm{P}_{4}$ or both hormones at $10^{-6} \mathrm{M}$. Ovaries were collected and labeled with antibodies against MSY2 and TRA98 or SYCP3 and VASA using immunocytochemistry. Msy2 mRNA expression during fetal and neonatal oocyte development was examined using RT-PCR. The expression of MSY2 and SYCP3 protein was followed during oocyte development using whole mount immunocytochemistry. SYCP3 protein was also followed over time using the meiotic surface spread technique.

\section{RNA isolation}

Fetal (13.5 dpc-18.5 dpc) and neonatal (PND1-PND5) ovaries were dissected in PBS, placed in RNAlater, flash frozen in liquid nitrogen and stored at $-80^{\circ} \mathrm{C}$. Total RNA was isolated using Qiagen's RNeasy Mini kit following the manufacturers instructions $(n=3 ; 50$ or 100 ovaries per pool for neonatal and fetal ovaries respectively). Ovaries were briefly lysed and homogenized using a motor pestle on ice and the mixture was then applied to a QIAshredder column. The ovarian tissue sample in the QIAshredder column was then centrifuged at 11,000 $\mathrm{g}$ for $2 \mathrm{~min}$. To isolate the RNA, the resulting flowthrough was applied to an RNeasy mini column which allowed the RNA to bind to the filter cartridge. RNA was eluted by washing from the filter and was concentrated using an RNeasy MinElute kit. The RNA which was isolated was briefly applied to an RNeasy MinElute spin column and after washing, RNA was eluted using $14 \mu \mathrm{l}$ of RNase-free water. The RNA concentration in the elutant was determined using an ND-1000 Spectrophotometer $(\lambda=260 / 280 \mathrm{~nm}$; Nanodrop Technologies, Inc., Wilmington, DE).

\section{First strand CDNA synthesis and real-time polymerase chain reaction (PCR)}

Total RNA $(0.5 \mu \mathrm{g})$ was reverse transcribed into cDNA using the Superscript III One-Step RT-PCR System. The cDNA was diluted in RNase-free water (1:25). $2 \mu \mathrm{l}$ of diluted cDNA was amplified on a Rotor-Gene 3000 using Quantitect ${ }^{\mathrm{Tm}}$ SYBR Green PCR kit and custom designed primers for Msy2 (forward primer: 5' CCC TGG CAA CCA GGC GAC GG 3'; reverse primer: 5' TGA CTG TGC CCA GGA CTT GGA TTG 3'; NCBI Genbank accession number NM_016875), and $\beta$-actin (forward primer: 5' AGT GTG ACG TTG ACA TCC GTA 3'; reverse primer: 5' GCC AGA GCA GTA ATC TAA TTA T 3'; NCBI Genbank accession number NM_007393). The cycling program consisted of a $15 \mathrm{~min}$ hold at $95^{\circ} \mathrm{C}$ and 45 cycles of: denaturing at $95^{\circ} \mathrm{C}$ for $15 \mathrm{~s}$, annealing at $58^{\circ} \mathrm{C}$ for $15 \mathrm{~s}$, and extension at $72{ }^{\circ} \mathrm{C}$ for $20 \mathrm{~s}$ at which point data were acquired. Determination of product melt conditions was done using a temperature gradient from $72{ }^{\circ} \mathrm{C}$ to $99^{\circ} \mathrm{C}$ with a $1{ }^{\circ} \mathrm{C}$ increase at each step. $\beta$-actin expression remained constant across all ages and therefore each sample was normalized to $\beta$-actin before quantification.

\section{Immunocytochemistry}

Once ovaries were harvested, they were fixed with 5.3\% EM grade formaldehyde in PBS overnight at $4{ }^{\circ} \mathrm{C}$ and immunostained as previously described [16]. Briefly, ovaries went through a series of washes at room temperature in $0.1 \%$ Triton X-100 in $1 \mathrm{X}$ PBS (PT) and then $\mathrm{PT}+5 \%$ bovine serum albumin (BSA). Following washes, ovaries were incubated overnight with primary antibodies diluted in PT $+5 \%$ BSA at $4{ }^{\circ} \mathrm{C}$ (see Table 1 for antibodies and dilutions). After overnight incubation in primary antibodies, ovaries were washed in PT $+1 \%$ BSA treated with RNase A and labeled with propidium iodide or TOTO3. Ovaries were then incubated with preabsorbed secondary antibodies (see Table 2 for secondary antibodies) at a dilution of 1:200 overnight at $4{ }^{\circ} \mathrm{C}$.

Table 1 Primary Antibodies and Dilutions Used

\begin{tabular}{|c|c|c|c|c|}
\hline Primary Antibody & Company & Catalog \# & Species Made In & Dilution \\
\hline MSY2 (C-15) & Santa Cruz Biotechnology & $\begin{array}{l}\text { sc-21,316 } \\
\text { Lot \#: C0615 }\end{array}$ & Goat & $1: 100$ \\
\hline SYCP3 (D-1) & Santa Cruz Biotechnology & $\begin{array}{l}\text { sc- } 74,569 \\
\text { Lot \#: J1314 }\end{array}$ & Mouse & $\begin{array}{l}\text { 1:200 (whole mount) } \\
\text { 1:50 (surface spreads) }\end{array}$ \\
\hline TRA98 & B-Bridge & $\begin{array}{l}\text { 73-003 } \\
\text { Lot \#: 141113A }\end{array}$ & Rat & $1: 500$ \\
\hline VASA & Abcam & $\begin{array}{l}\text { ab-13,840 } \\
\text { Lot \#: GR172688-1 }\end{array}$ & Rabbit & $1: 250$ \\
\hline
\end{tabular}


Table 2 Secondary Antibodies and Dilutions Used

\begin{tabular}{|c|c|c|c|c|}
\hline Secondary Antibody & Company & Catalog \# & Species Made In & Dilution \\
\hline Alexa Fluor 488 Donkey Anti-Goat & Molecular Probes/Invitrogen & A11055 & Donkey & $1: 200$ \\
\hline Alexa Fluor 488 Donkey Anti-Rat & Molecular Probes/Invitrogen & A21208 & Donkey & $1: 200$ \\
\hline Alexa Fluor 488 Goat Anti-Mouse & Molecular Probes/Invitrogen & A11029 & Goat & $1: 200$ \\
\hline Alexa Fluor 488 Goat Anti-Rabbit & Molecular Probes/Invitrogen & A11008 & Goat & 1:200 \\
\hline Alexa Fluor 568 Donkey Anti-Goat & Molecular Probes/Invitrogen & A11057 & Donkey & $1: 200$ \\
\hline Alexa Fluor 568 Goat Anti-Mouse & Molecular Probes/Invitrogen & A11004 & Goat & $1: 200$ \\
\hline
\end{tabular}

Negative controls using only secondary antibodies were previously tested in the lab for all antibodies used. Ovaries were washed in $\mathrm{PT}+1 \% \mathrm{BSA}$, rinsed in PBS, placed in Vectashield, mounted and observed by confocal microscopy on a Zeiss LSM 710 confocal microscope.

\section{Meiotic surface spreads}

Ovaries were harvested, incubated in Hypotonic Extraction Buffer (30 mM Tris, $50 \mathrm{mM}$ sucrose, $17 \mathrm{mM}$ trisodium citrate dihydrate, $5 \mathrm{mM}$ EDTA, $0.5 \mathrm{mM}$ DTT, and $0.5 \mathrm{mM}$ phenylmethylsulphonyl fluoride (PMSF), $\mathrm{pH}$ 8.2) and then teased apart in $100 \mathrm{mM}$ sucrose. The cell suspension was dried down and fixed in $1 \%$ paraformaldehyde. Slides were incubated overnight in a humidity chamber at $37^{\circ} \mathrm{C}$. Slides were then air dried, washed in $0.4 \%$ PhotoFlo, air dried again and stored at $-20{ }^{\circ} \mathrm{C}$ until staining. Slides were washed in PBS, blocked with $2.5 \%$ goat serum and stained with antibodies against SYCP3 (see Table 1) diluted in $2.5 \%$ goat serum in a humidity chamber overnight at $4{ }^{\circ} \mathrm{C}$. Subsequently, slides were washed with $0.1 \%$ Tween in PBS and then incubated Alexa Fluor 488 Goat Anti-Mouse secondary antibodies (see Table 2) diluted in $2.5 \%$ goat serum for 1 hour. Slides were washed with $0.1 \%$ Tween in PBS, mounted in a $1: 1$ solution of Vectashield and $2 \mu \mathrm{g} / \mathrm{ml}$ DAPI and stored at $-20^{\circ} \mathrm{C}$.

\section{In vitro ovary organ culture}

Ovaries dissected at $17.5 \mathrm{dpc}$ were placed in culture. Ovaries were cultured in 4-well culture plates in drops of media on $0.4 \mu \mathrm{M}$ floating filters (Millicell- CM; Millipore Corp., Bedford, MA) in 0.4 ml DMEM-Ham's F-12 media supplemented with penicillin-streptomycin, 5X ITS-X (Life Technologies, Inc., Grand Island, NY), 0.1\% BSA, $0.1 \%$ albumax, and $0.05 \mathrm{mg} / \mathrm{ml} \mathrm{L}$-ascorbic acid. $\mathrm{E}_{2}$ and $\mathrm{P}_{4}$ (Sigma Chemical Co., St. Louis, MO) were dissolved in dimethylsulfoxide (DMSO) at a concentration of $0.1 \mathrm{M}$ and then added to culture media to achieve the desired final concentration. DMSO was added to media at the same percentage as a vehicle control. Ovaries were exposed daily to DMSO, $\mathrm{E}_{2}, \mathrm{P}_{4}$ or both hormones at $10^{-6} \mathrm{M}$ ( $n=5$ ovaries per treatment group). Ovaries were divided randomly among the treatment groups. Ovaries were fixed in formaldehyde and immunostained as described above.

\section{Statistical analysis}

Data are represented as mean \pm SEM of nontransformed data. Statistical analyses using transformed data were performed using GraphPad Prism version 6 (GraphPad Software, San Diego, CA). Statistical differences $(P<$ 0.05 ) among the means were evaluated using one-way ANOVA followed by Newman-Keuls multiple comparisons test. Effects of $\mathrm{E}_{2}$ and $\mathrm{P}_{4}$ on MSY2 and SYCP3 expression were analyzed using one-way ANOVA followed by Dunnett's multiple comparisons test. Statistical analyses of real time PCR data were performed using Statview 5.0.1 (SAS Institute Inc., Cary, NC). Differences between fold increases in mRNA levels over various time points were evaluated by one-way ANOVA followed by Bonferroni-Dunn's post hoc test $(P<0.0005)$.

\section{Results}

\section{Exposure to steroid hormones alters Msy2 expression}

Our lab previously showed that exogenous exposure of developing ovaries to estradiol or progesterone reduced cyst breakdown and follicle formation and together had an additive effect [3]. Here, we examined effects of exogenous hormone exposure on meiotic prophase I progression of oocytes from fetal ovaries by treatment with estradiol and/or progesterone. $17.5 \mathrm{dpc}$ ovaries were harvested and grown in vitro using an organ culture system. Ovaries were grown for 5 days in DMSO, $10^{-6} \mathrm{M}$ estradiol, $10^{-6} \mathrm{M}$ progesterone, or $10^{-6} \mathrm{M}$ estradiol + progesterone until they reached the equivalent of PND3 (Fig. 1a). An antibody against MSY2, a reported marker of diplotene arrest was used to follow meiotic progression. Ovaries were fixed and labeled with MSY2 and the oocyte marker, TRA98 using immunocytochemistry and then analyzed by confocal microscopy (Fig. 1b-e). Oocytes were marked as either expressing MSY2 strongly, weakly, or not at all in order to analyze the effects of hormone exposure on meiotic progression. Progesterone significantly lowered the percent of oocytes strongly expressing MSY2 and significantly increased the percent of oocytes with no MSY2 expression (Fig. 1f). Estradiol alone as well as the combination of estradiol and progesterone did not have a significant impact on MSY2 expression. 


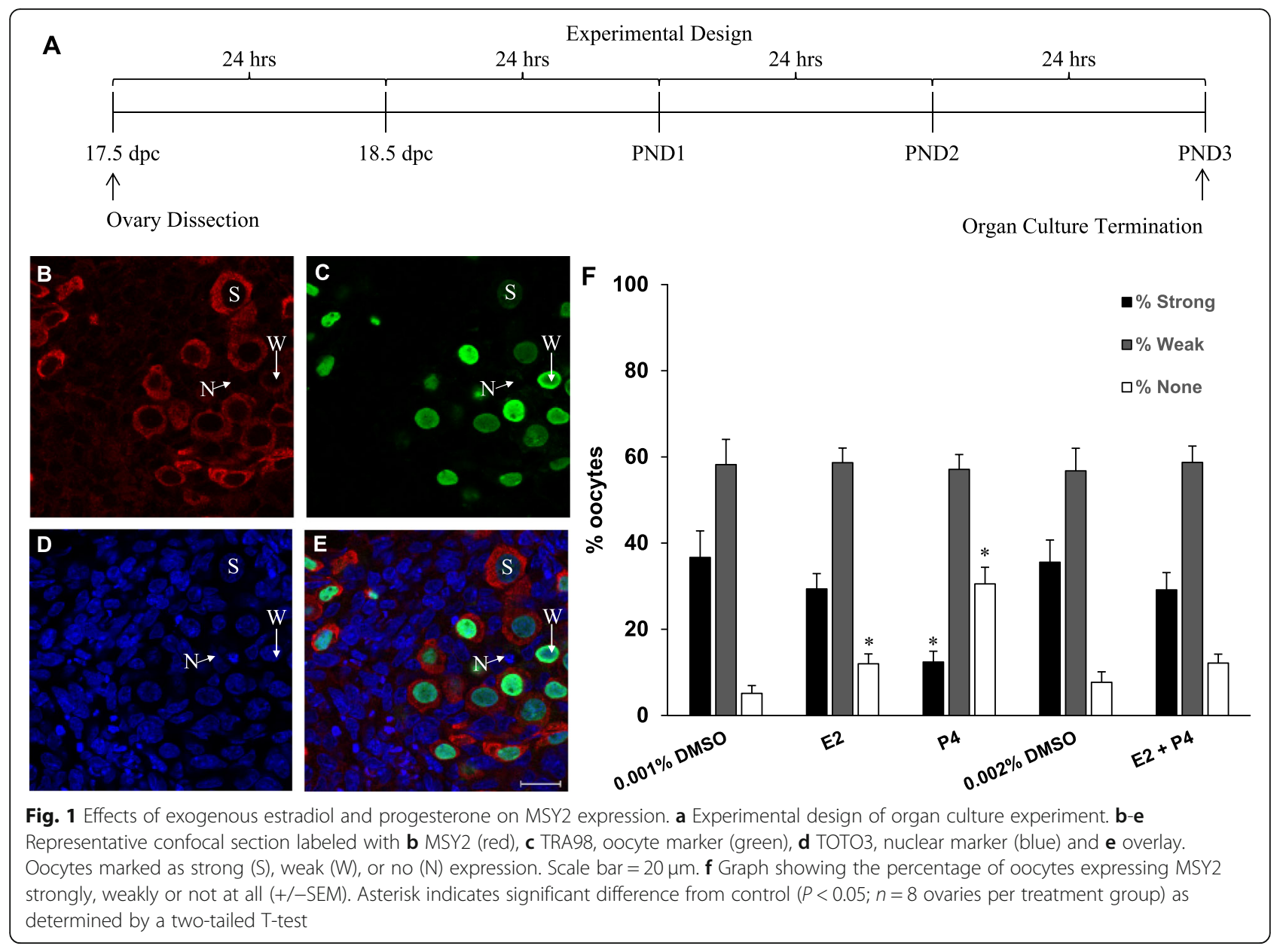

\section{MSY2 expression correlates with diplotene arrest but is not a diplotene stage marker}

MSY2 expression has previously been used to indicate arrest at the diplotene stage of meiotic prophase I [17, 22]. To confirm that MSY2 is a diplotene arrest marker we examined MSY2 mRNA and protein expression during fetal and neonatal oocyte development. First, we measured the levels of Msy2 mRNA by qPCR in ovaries from $13.5 \mathrm{dpc}$ to PND 5 (Fig. 2a). A slight increase of Msy2 mRNA is observed at $17.5 \mathrm{dpc}$ with a statistically significant increase at $18.5 \mathrm{dpc}$ correlating with the increase in diplotene oocytes observed by our lab and others starting at $17.5 \mathrm{dpc}[1,8]$. We also examined MSY2 protein expression using whole mount immunostaining in ovaries from $15.5 \mathrm{dpc}$ through PND 5. At each timepoint, oocytes were counted and marked as either strongly expressing or weakly expressing MSY2 (Fig. 2c-e). Strong expression of MSY2 within an oocyte was taken to mean that the cell had reached and arrested at the diplotene stage of meiotic prophase I. Approximately $40 \%$ of the oocytes strongly expressed MSY2 at $15.5 \mathrm{dpc}$ and this increased over time to PND5 when almost all oocytes $(\sim 94 \%)$ were strongly expressing MSY2 (Fig. 2b). The increase in oocytes strongly expressing
MSY2 correlates with the expected increase in oocytes arriving at and arresting at the diplotene stage of meiotic prophase I. However, we were surprised that $40 \%$ of the oocytes were already expressing MSY2 at high levels even though it is known that oocytes don't start to arrive at diplotene until $17.5 \mathrm{dpc}$ thus we conclude that while MSY2 expression correlates with arrival at the diplotene stage it is not a marker for diplotene arrest per se.

\section{SYCP3 can be used to follow meiotic progression in surface spreads and in whole mount immunocytochemistry}

We investigated alternative methods to follow meiotic progression including the surface spread technique. This method allows a more precise identification of meiotic prophase I substage but involves the disassociation of the tissue resulting in the loss of any cellular structure. Nuclei prepared using the surface spread technique are then labeled with an antibody against SYCP3 which labels the synaptonemal complex formed between homologous chromosomes at the pachytene stage. This labeling can be used to stage nuclei and oocytes labeled with SYCP3 using this technique at each stage of meiotic 


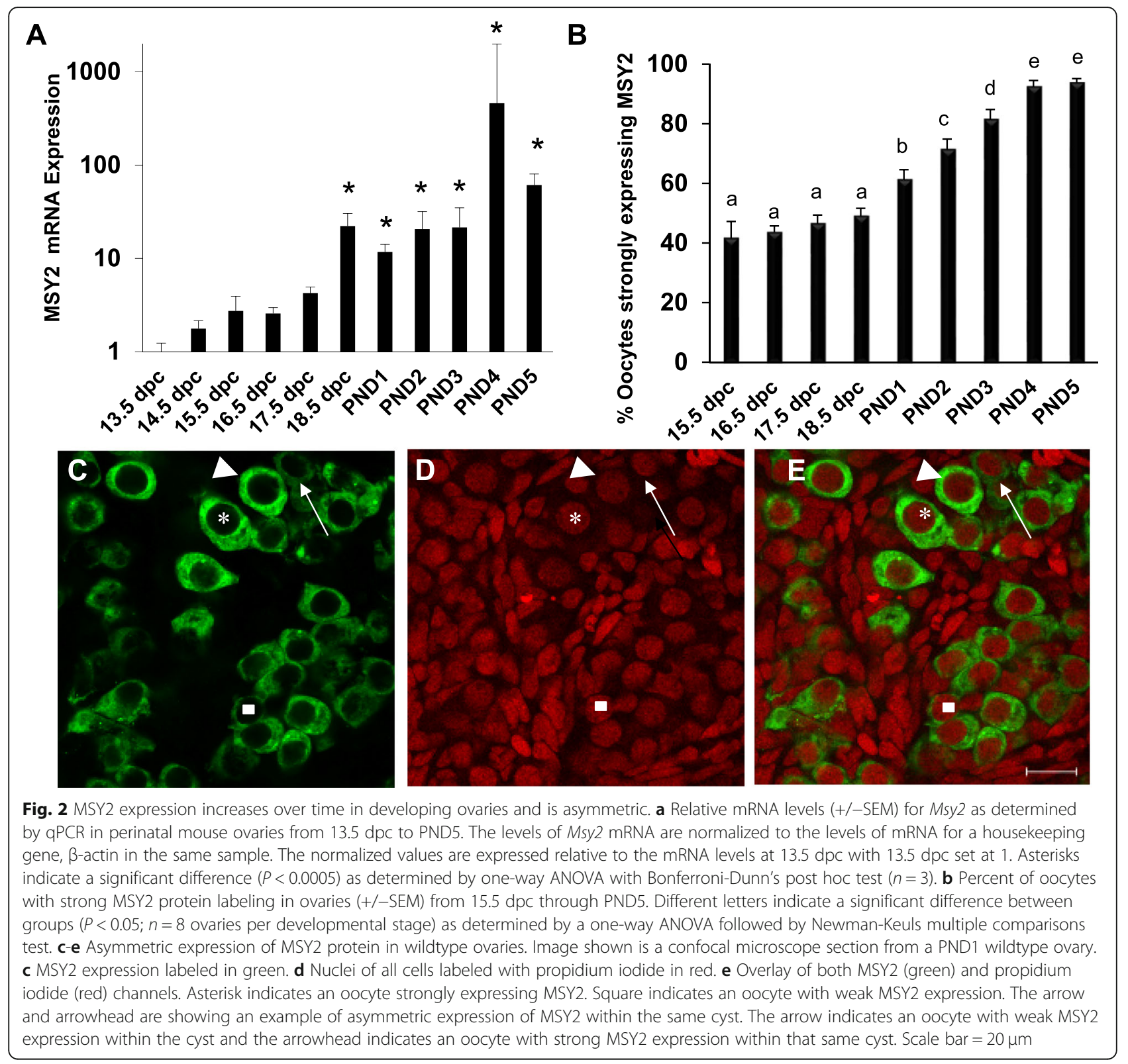

prophase I are shown in Fig. 3a-e. We used this technique to determine the percent of oocytes at each stage from $16.5 \mathrm{dpc}$ to PND4 (Fig. 3f). We found the peak percentage of oocytes in the pachytene stage was $44 \%$ at PND1.

We also examined the expression of SYCP3 in whole mount immunohistochemistry which is upregulated as the germ cells enter meiosis and at the pachytene stage has a very striking localization as condensed "strings" between homologous chromosomes (Fig. 4a-c). SYCP3 expression was analyzed within the female germ cells from $13.5 \mathrm{dpc}$ through PND 5 and the percent of pachytene stage oocytes was determined (Fig. 4d). Oocytes in the pachytene stage were not observed until $16.5 \mathrm{dpc}$. After
$16.5 \mathrm{dpc}$, the number of pachytene labeled oocytes increased until PND1 where a peak of approximately 55\% was observed. Starting at PND2, the number of oocytes at the pachytene stage significantly decreased and no cells were observed to be in pachytene after PND3.

\section{Exposure to steroid hormones delays progression through prophase I}

$17.5 \mathrm{dpc}$ ovaries were again harvested and cultured for 5 days with DMSO vehicle, $10^{-6} \mathrm{M}$ estradiol, $10^{-6} \mathrm{M}$ progesterone, and $10^{-6} \mathrm{M}$ estradiol + progesterone until they reached PND3 similar to Fig. 1a. This time, ovaries were labeled for SYCP3 and the germ cell marker, VASA using whole mount immunocytochemistry and then 

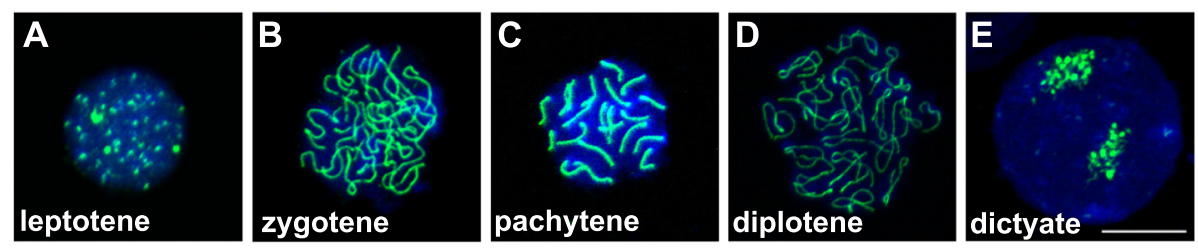

$\mathbf{F}$
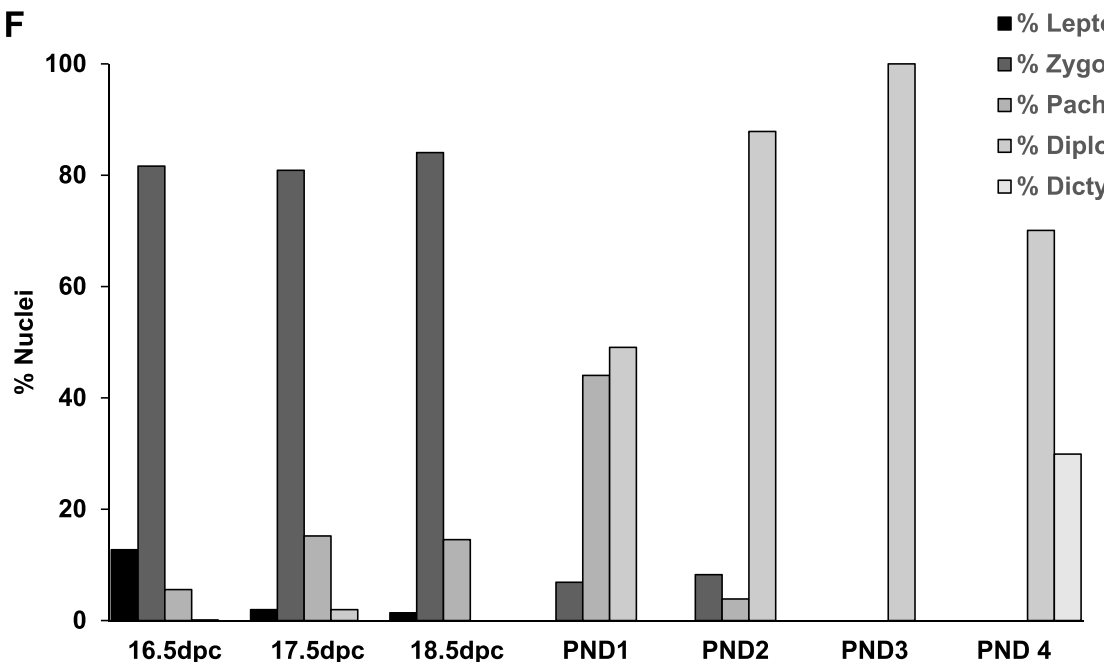

Fig. 3 Analysis of meiotic prophase I progression using surface spreads. a-e Examples of nuclei at each substage of prophase one labeled with SYCP3 (green) and DAPI (blue). a Nucleus in the leptotene substage showing chromosomes beginning to condense. b Nucleus in the zygotene substage showing homologous chromosomes beginning to come together and the synaptonemal complex starting to form. c A pachytene nucleus showing completion of synapsis. $\mathbf{d}$ A diplotene arrested nucleus showing chromosomes that have begun to separate but remain attached at sites of crossing over. e A late-diplotene/dictyate nucleus, with chromosomes condensed and at opposite poles. Scale bar $=20 \mu \mathrm{m}$. $\mathbf{f}$ Percent of oocyte nuclei in each stage of prophase one from $17.5 \mathrm{dpc}$ to PND4 determined using the meiotic surface spread assay with SYCP3 staining. Approximately 200 nuclei were counted for each age of development

analyzed by confocal microscopy (Fig. 5a-d). The percent of pachytene oocytes was determined in order to analyze the effects of hormone exposure on meiotic progression. Ovaries treated with estradiol and progesterone together had a significant increase in the percent of oocytes in the pachytene stage suggesting that progression through meiotic prophase I was delayed (Fig. 5e).

\section{Discussion}

Here, we show that MSY2 expression in oocytes is reduced by progesterone but not estradiol alone or estradiol and progesterone in combination using ovary organ culture. In addition, while MSY2 upregulation correlates with arrival at the diplotene stage, is a not a diplotene stage marker as some pre-diplotene oocytes highly express MSY2. SYCP3 can be used to follow progress of oocytes through meiotic prophase I using both surface spreads and whole mount immunostaining with the pachytene stage especially prominent. Finally, estradiol and progesterone together but not either hormone individually delay prophase I progression as determined by the expression pattern of SYCP3 in whole mount immunostaining.
Our data suggest that MSY2 protein levels increase as oocytes approach the diplotene phase of meiotic prophase I but is not a diplotene stage marker per se. As shown in Fig. 2b, MSY2 is strongly expressed in oocytes even at $15.5 \mathrm{dpc}$ before any oocytes have reached the diplotene stage. MSY2 is a conserved RNA binding protein specifically expressed in germ cells and required for fertility [9, 24]. In male germ cells it is important post-meiotically during spermiogenesis [25]. In oocytes, MSY2 protein regulates mRNA stability as oocyte increases in size [14]. Msy2 mutant oocytes have many abnormalities such as aberrant spindle formation and chromosome congression during meiosis II, however, there is no evidence for a role of MSY2 in meiotic prophase I. Likely, the expression of MSY2 is upregulated during meiotic prophase I in preparation for future oocyte growth and later meiotic functions.

Previous research has shown that estrogen and progesterone have negative effects on the development process of female germ cells. Progesterone and estradiol, the phytoestrogen genistein, as well as synthetic estrogens all disrupt cyst breakdown and follicle formation $[3,11,12]$ thereby leading to a potential decrease in viable egg cells 

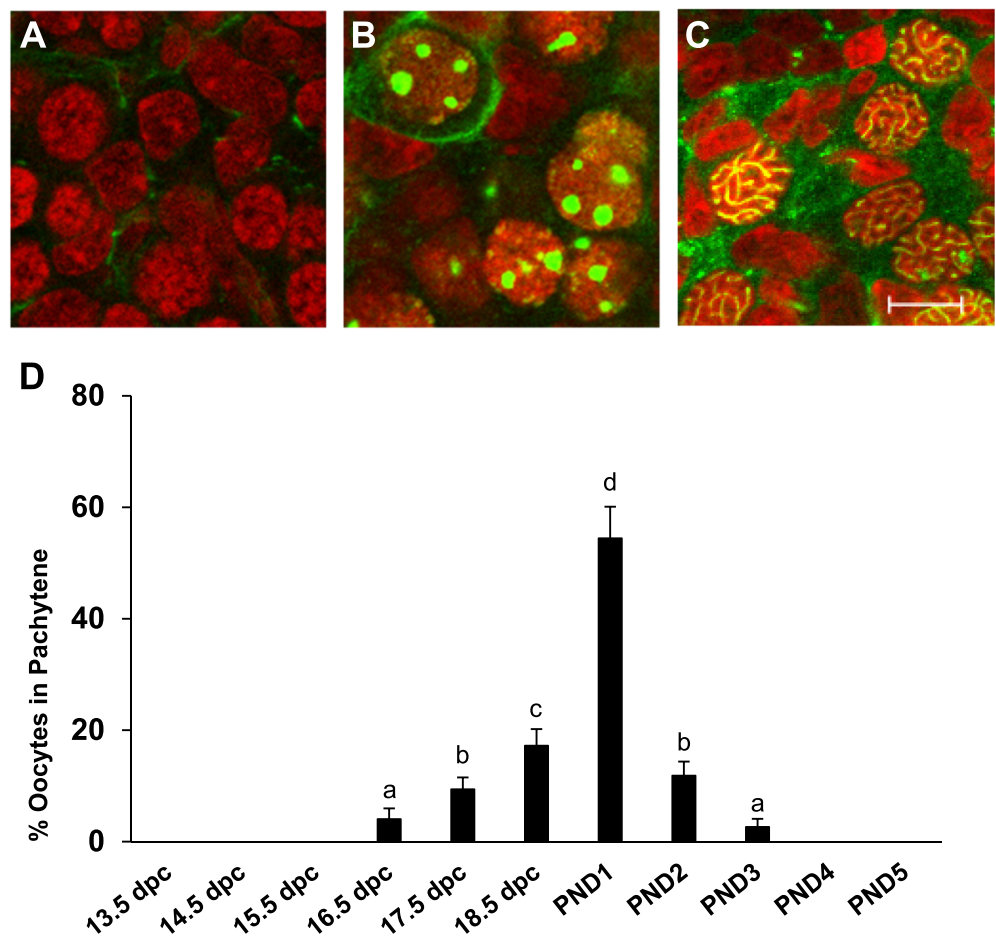

Fig. 4 The percentage of pachytene oocytes peaks at PND1 as determined by SYCP3 labeling. a-c Representative confocal microscope sections labeled for SYCP3 (green) and nuclear marker propidium iodide (red) at a $13.5 \mathrm{dpc}$ showing unlabeled mitotic nuclei, b $15.5 \mathrm{dpc}$ showing prepachytene meiotic nuclei and $\mathbf{c}$ PND1 showing pachytene meiotic nuclei. Scale bar $=10 \mu \mathrm{m}$. $\mathbf{d}$ Percent of oocytes in the pachytene stage of development in ovaries from $13.5 \mathrm{dpc}$ through PND5 determined by whole mount SYCP3 expression (+/-SEM). Different letters indicate a significant difference between groups ( $P<0.05 ; n=8$ ovaries per developmental stage) as determined by a one-way ANOVA followed by Newman-Keuls multiple comparisons test
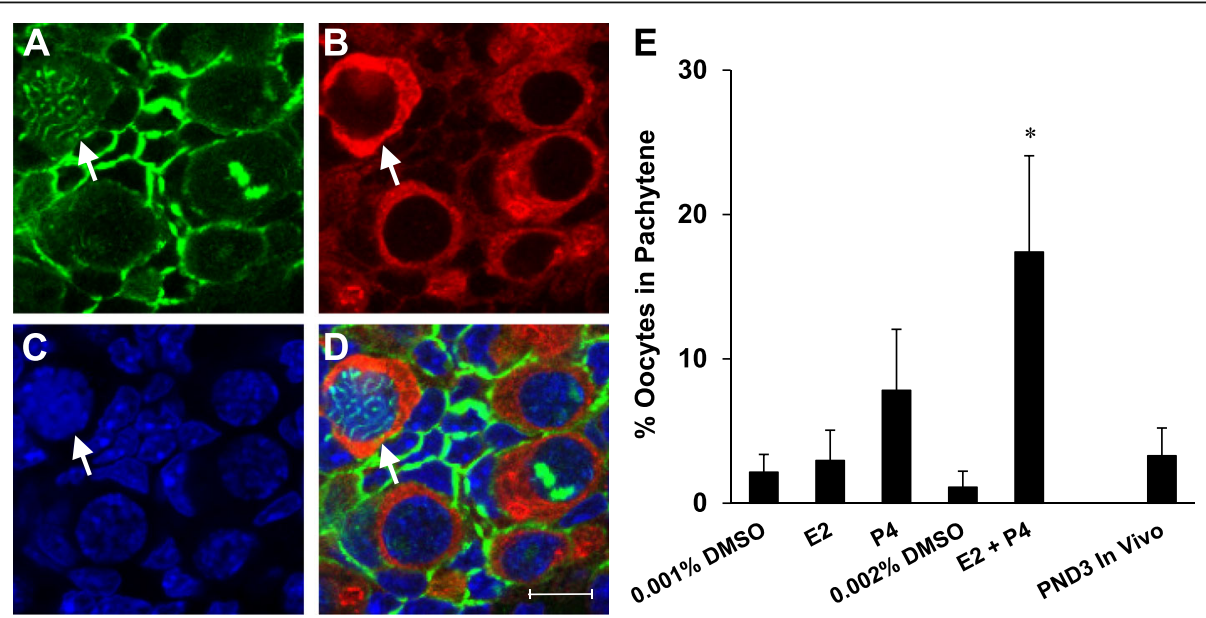

Fig. 5 Effects of estradiol and progesterone on progression through meiotic prophase I. a-d Representative confocal section labeled with a SYCP3 (green) showing oocyte with pachytene expression pattern (arrow), b VASA, oocyte marker (red), c TOTO3, nuclear marker (blue) and $\mathbf{d}$ overlay. Scale bar $=10 \mu \mathrm{m}$. e Graph showing the percentage of oocytes in the pachytene stage as determined by SYCP3 expression pattern $(+/$-SEM). Asterisk indicates significant difference from control $(P<0.05 ; n=8$ ovaries per treatment group) as determined by a two-tailed T-test 
later in life. In some instances, the number of oocytes present is also affected, but not as consistently. Here, ovaries were treated with estradiol alone, progesterone alone, or both estradiol and progesterone and effects on meiotic progression examined using SYCP3 expression in whole mount immunostaining. The number of oocytes found in the pachytene stage significantly increased only in the estradiol and progesterone treatment group indicating that treatment with both hormones delayed meiotic progression. Previous research has shown that when pregnant female mice were exposed to Bisphenol A (BPA), an estrogenic chemical, meiotic progression was disrupted by way of a disturbance of the synapsis and recombination of chromosome homologs [23]. Another study showed that progesterone acts through the progesterone receptor membrane component 1 (PGRMC1) to significantly delay or completely disrupt meiotic progression and therefore disrupt primordial follicle assembly [10]. The results of our organ culture agreed with these findings.

Our previous work investigating prophase I progression using standard histology demonstrated that progesterone but not estradiol or the combination of estradiol and progesterone delayed meiotic progression [8]. However, in the work presented here only the combination of estradiol and progesterone significantly affected progression through meiosis. One difference between the two studies is the mouse strain used. The CD1 outbred strain was used in our earlier study while here we used the B6 inbred strain. Interestingly, we also found that only progesterone alone reduced MSY2 expression.

We used two different molecular techniques to follow prophase I progression during perinatal oocyte development. The surface spread technique combined with a synaptonemal complex marker such as SYCP3 allows precise identification of prophase I substages. However, all structural information is lost with this method. The second technique, also using SYCP3 is whole mount immunostaining which preserves three dimensional structural information but does not allow precise identification of prophase substages though the pachytene stage is easy to identify. Using both techniques we found the largest percentage of pachytene oocytes at PND1 ( 45\% in surface spreads and $~ 55 \%$ in immunostaining). Thus, both techniques were able to be used to provide information regarding meiotic progression.

\section{Conclusions}

The ultimate outcome of perinatal oocyte development is the formation the ovarian reserve consisting of a pool of primordial follicles with each follicle containing a diplotene arrested oocyte. Here we demonstrated the impact of steroid hormone signaling on meiotic prophase I progression. Future work investigating additional mechanisms regulating progression through meiotic prophase I will be important to understand the production of a robust ovarian reserve.
Acknowledgements

The authors thank members of the Pepling lab for critical review of the manuscript.

\section{Authors' contributions}

DMB conducted organ culture experiments examining MSY2 and SYCP3 expression during perinatal oocyte development using whole mount immunocytochemistry. MRM conducted meiotic surface spread experiments. SD and CJM conducted RT-PCR experiments with assistance from PBH for data analysis. MEP designed experiments, helped with data analysis and interpretation, obtained funding to support the project and drafted the manuscript. All authors read and approved the final manuscript.

\section{Funding}

This work was supported in part by grants from the National Science Foundation IOS-1146940 and the National Institutes of Health R15HD075257 (to MEP).

\section{Availability of data and materials}

The datasets analyzed during the current study are available from the corresponding author on reasonable request.

Ethics approval and consent to participate

This work was approved by the Syracuse University Institutional Care and Use Committee (IACUC protocols \# 14-006 and 17-003).

Consent for publication

Not applicable

\section{Competing interests}

The authors declare that they have no competing interests.

\section{Author details}

'Department of Biology, Syracuse University, 107 College Place, Syracuse, NY 13244, USA. ${ }^{2}$ Present address: University of Nebraska Medical Center, Omaha, NE, USA. ${ }^{3}$ Department of Physiology, College of Medicine, The University of Arizona, Tucson, AZ, USA. ${ }^{4}$ Present address: PRA Health Sciences Lenexa, Lenexa, KS, USA.

Received: 30 August 2019 Accepted: 21 November 2019

Published online: 02 December 2019

References

1. Borum K. Oogenesis in the mouse. A study of the origin of the mature ova. Exp Cell Res. 1961;45(1):39-47.

2. Bullejos M, Koopman P. Germ cells enter meiosis in a rostro-caudal wave during development of the mouse ovary. Mol Reprod Dev. 2004; 68(4):422-8.

3. Chen Y, Jefferson WN, Newbold RR, Padilla-Banks E, Pepling ME. Estradiol, progesterone, and genistein inhibit oocyte nest breakdown and primordial follicle assembly in the neonatal mouse ovary in vitro and in vivo. Endocrinology. 2007;148(8):3580-90.

4. Cohen PE, Holloway JK. Predicting gene networks in human oocyte meiosis. Biol Reprod. 2010;82(3):469-72

5. Cohen PE, Pollack SE, Pollard JW. Genetic analysis of chromosome pairing, recombination, and cell cycle control during first meiotic prophase in mammals. Endocr Rev. 2006;27(4):398-426.

6. Di Carlo AD, Travia G, De Felici M. The meiotic specific synaptonemal complex protein SCP3 is expressed by female and male primordial germ cells of the mouse embryo. Int J Dev Biol. 2000;44(2):241-4.

7. Dokshin GA, Baltus AE, Eppig JJ, Page DC. Oocyte differentiation is genetically dissociable from meiosis in mice. Nat Genet. 2013;45(8):877-83.

8. Dutta S, Burks DM, Pepling ME. Arrest at the diplotene stage of meiotic prophase I is delayed by progesterone but is not required for primordial follicle formation in mice. Reprod Biol Endocrinol. 2016;14(1):82.

9. Gu W, Tekur S, Reinbold R, Eppig JJ, Choi YC, Zheng JZ, Murray MT, Hecht NB. Mammalian male and female germ cells express a germ cell-specific $Y$ box protein, MSY2. Biol Reprod. 1998;59(5):1266-74.

10. Guo M, Zhang C, Wang Y, Feng L, Wang Z, Niu W, Du X, Tang W, Li Y, Wang $C$, Chen Z. Progesterone receptor membrane component 1 mediates 
progesterone-induced suppression of oocyte meiotic prophase I and primordial Folliculogenesis. Sci Rep. 2016;6:36869.

11. Jefferson W, Newbold R, Padilla-Banks E, Pepling M. Neonatal genistein treatment alters ovarian differentiation in the mouse: inhibition of oocyte nest breakdown and increased oocyte survival. Biol Reprod. 2006;74(1):161-8.

12. Karavan JR, Pepling ME. Effects of estrogenic compounds on neonatal oocyte development. Reprod Toxicol. 2012;34(1):51-6.

13. Lei L, Spradling AC. Mouse primordial germ cells produce cysts that partially fragment prior to meiosis. Development. 2013;140(10):2075-81.

14. Medvedev S, Pan H, Schultz RM. Absence of MSY2 in mouse oocytes perturbs oocyte growth and maturation, RNA stability, and the transcriptome. Biol Reprod. 2011;85(3):575-83.

15. Menke DB, Koubova J, Page DC. Sexual differentiation of germ cells in XX mouse gonads occurs in an anterior-to-posterior wave. Dev Biol. 2003; 262(2):303-12.

16. Murphy K, Carvajal L, Medico L, Pepling M. Expression of Stat3 in germ cells of developing and adult mouse ovaries and testes. Gene Expr Patterns. 2005;5(4):475-82.

17. Paredes A, Garcia-Rudaz C, Kerr B, Tapia V, Dissen GA, Costa ME, Cornea A, Ojeda SR. Loss of synaptonemal complex protein-1, a synaptonemal complex protein, contributes to the initiation of follicular assembly in the developing rat ovary. Endocrinology. 2005;146(12):5267-77.

18. Pepling ME. From primordial germ cell to primordial follicle: mammalian female germ cell development. Genesis. 2006;44(12):622-32.

19. Pepling ME, Spradling AC. Female mouse germ cells form synchronously dividing cysts. Development. 1998;125(17):3323-8.

20. Pepling ME, Spradling AC. Mouse ovarian germ cell cysts undergo programmed breakdown to form primordial follicles. Dev Biol. 2001;234(2): 339-51.

21. Pepling ME, Sundman EA, Patterson NL, Gephardt GW, Medico L Jr, Wilson KI. Differences in oocyte development and estradiol sensitivity among mouse strains. Reproduction. 2010:139(2):349-57.

22. Soyal SM, Amleh A, Dean J. FIGalpha, a germ cell-specific transcription factor required for ovarian follicle formation. Development. 2000;127(21): 4645-54.

23. Susiarjo M. Hassold TJ, Freeman E, Hunt PA. Bisphenol a exposure in utero disrupts early oogenesis in the mouse. PLoS Genet. 2007;3(1):e5.

24. Yang J, Medvedev S, Yu J, Tang LC, Agno JE, Matzuk MM, Schultz RM, Hecht NB. Absence of the DNA-/RNA-binding protein MSY2 results in male and female infertility. Proc Natl Acad Sci U S A. 2005;102(16):5755-60.

25. Yang J, Morales CR, Medvedev S, Schultz RM, Hecht NB. In the absence of the mouse DNA/RNA-binding protein MSY2, messenger RNA instability leads to spermatogenic arrest. Biol Reprod. 2007;76(1):48-54.

26. Yang MY, Fortune JE. The capacity of primordial follicles in fetal bovine ovaries to initiate growth in vitro develops during mid-gestation and is associated with meiotic arrest of oocytes. Biol Reprod. 2008;78(6):1153-61.

\section{Publisher's Note}

Springer Nature remains neutral with regard to jurisdictional claims in published maps and institutional affiliations.

Ready to submit your research? Choose BMC and benefit from:

- fast, convenient online submission

- thorough peer review by experienced researchers in your field

- rapid publication on acceptance

- support for research data, including large and complex data types

- gold Open Access which fosters wider collaboration and increased citations

- maximum visibility for your research: over $100 \mathrm{M}$ website views per year

At $\mathrm{BMC}$, research is always in progress.

Learn more biomedcentral.com/submissions 